\title{
CYP2C19 genotype-based phase I studies of a c-Met inhibitor tivantinib in combination with erlotinib, in advanced/metastatic non-small cell lung cancer
}

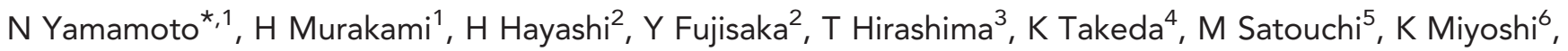 \\ S Akinaga ${ }^{6}$, T Takahashi $^{1}$ and K Nakagawa ${ }^{2}$ \\ 1 Division of Thoracic Oncology, Shizuoka Cancer Center, 1007, Shimonagakubo, Nagaizumi-cho, Sunto-gun, Shizuoka 411-8777, \\ Japan; ${ }^{2}$ Department of Medical Oncology, Kinki University Faculty of Medicine, 337-2, Ohno-higashi, Osakasayama-shi, Osaka \\ 589-8511, Japan; ${ }^{3}$ Department of Thoracic Malignancy, Osaka Prefectural Medical Center for Respiratory and Allergic Diseases, \\ 3-7-1, Habikino, Habikino-shi, Osaka 583-8588, Japan; ${ }^{4}$ Department of Clinical Oncology, Osaka City General Hospital, 2-13-22, \\ Miyakojimahondori, Miyakojima-ku, Osaka 534-0021, Japan; ${ }^{5}$ Thoracic Oncology, Hyogo Cancer Center, 13-70, Kitaouji-cho, \\ Akashi, Hyogo 673-8558, Japan and ' Kyowa Hakko Kirin Co., Ltd, 1-6-1, Ohtemachi, Chiyoda-ku, Tokyo 100-8185, Japan
}

Background: A previous clinical study in non-small cell lung cancer (NSCLC) patients in Western countries suggested the potential for combination of a first-in-class non-ATP-competitive c-Met inhibitor tivantinib with an epidermal growth factor receptor-tyrosine kinase inhibitor erlotinib. Polymorphisms of CYP2C19, the key metabolic enzyme for tivantinib, should be addressed to translate the previous Western study to Asian population, because higher incidence of poor metabolisers (PMs) is reported in Asian population.

Methods: Japanese patients with advanced/metastatic NSCLC received tivantinib in combination with erlotinib to evaluate safety and pharmacokinetics. Doses of tivantinib were escalated separately for extensive metabolisers (EMs) and PMs.

Results: Tivantinib, when combined with erlotinib, was well tolerated up to $360 \mathrm{mg}$ BID for EMs and $240 \mathrm{mg}$ BID for PMs, respectively. Among 25 patients (16 EMs and 9 PMs), the adverse events (AEs) related to tivantinib and/or erlotinib (>20\%, any grade) were rash, diarrhoea, dry skin and nausea. Grade $\geqslant 3$ AEs were leukopenia, anaemia and neutropenia. No dose-limiting toxicity was observed. Pharmacokinetics profile of tivantinib was not clearly different between the combination and monotherapy. Three partial response and three long-term stable disease ( $\geqslant 24$ weeks) were reported.

Conclusion: Two doses of tivantinib in combination with erlotinib were recommended based on CYP2C19 genotype: $360 \mathrm{mg}$ BID for EMs and $240 \mathrm{mg}$ BID for PMs.

Lung cancer is one of the most common malignancies in the world. The annual incidence and mortality in eastern Asia (Japan, China, Korea and Mongolia) are estimated to be 650000 and 550000 , respectively (Ferlay et al, 2010). About $85 \%$ of lung cancer cases are histologically diagnosed as non-small cell lung cancer (NSCLC). A platinum-based chemotherapy is currently the first-line treatment for advanced or recurrent NSCLC without mutated epidermal growth factor receptor (EGFR). Many options are available for second- and third-line treatment of NSCLCs, however, the effects of these therapies are modest with a 5-year survival rate of $15 \%$ (Jemal et al, 2008).

\footnotetext{
*Correspondence: Dr N Yamamoto; E-mail: nbyamamo@wakayama-med.ac.jp
}

Received 27 May 2013; revised 23 August 2013; accepted 4 September 2013; published online 29 October 2013 
Epidermal growth factor receptor tyrosine kinase inhibitors (EGFR-TKIs) have been recently developed for the treatment of advanced or recurrent NSCLC and proven to be particularly effective in the NSCLC harbouring driver mutations in EGFRs, such as exon 19-deletion or L858R mutation (Sharma et al, 2007). The incidence of the EGFR driver mutation was higher in Asian NSCLC; 32\% in Asians while 7\% in non-Asians (Mitsudomi and Yatabe, 2007). Currently, the acquired resistance to EGFR-TKIs is an emerging clinical issue. The putative mechanisms of the acquired resistance may include T790M secondary mutations, loss of PTEN and activations of c-Met axis. The c-Met axis activations may include c-Met amplification, c-Met overexpression and hepatocyte growth factor (HGF) upregulation (Suda et al, 2012).

A receptor tyrosine kinase, c-Met, and its ligand, HGF, are overexpressed in many types of cancer, including NSCLC, and may contribute to driving cancer cell proliferation and dissemination, thus leading to disease progression and metastasis (Tavian et al, 2000; Trusolino et al, 2001; Comoglio et al, 2008; Yap and de Bono, 2010). In addition, the c-Met axis activations have been observed in NSCLC regardless of EGFR mutation status and are correlated with poor prognosis (Beviglia et al, 1997; Qian et al, 2002; Qiao et al, 2002; Takeuchi et al, 2003).

Tivantinib (formerly ARQ 197) is a selective, oral, non-ATPcompetitive, small-molecule inhibitor of c-Met (Eathiraj et al, 2011) under extensive clinical evaluation. Clinical studies of tivantinib have been conducted primarily in Western countries so far. A Western phase II study (ARQ 197-209) indicated clinical benefits of tivantinib in combination with an EGFR-TKI, erlotinib, for patients with previously treated non-squamous NSCLC, and those benefits included significantly prolonged progression-free survival (Sequist et al, 2011). The dose of tivantinib used in the Western phase II/III studies in NSCLC was $360 \mathrm{mg}$ BID taken at least $1 \mathrm{~h}$ before or $2 \mathrm{~h}$ after a meal (i.e., between meals), and was not adjusted for polymorphisms of CYP2C19, which is the key enzyme responsible for metabolising tivantinib. Two major CYP2C19 polymorphisms (CYP2C19*2 and CYP2C19*3), which lead to a functional deficiency of CYP2C19, are known, and it is well established that the ratio of the CYP2C19 poor metabolisers (PMs), who are defined as the homozygote of either CYP2C19 2 or CYP2C19*3 (excluding wild-type CYP2C19*1), is around $20 \%$ in Asian populations, compared with $3 \%$ in Caucasians (Kubota et al, 2001; Scordo et al, 2002; Sim et al, 2006).

To translate the results from Western studies to the Asian population, we have to consider the two major CYP2C19 polymorphisms. The Western population is comprised mainly of CYP2C19 extensive metabolisers (EMs), who are defined as possessing at least one allele of wild-type $\mathrm{CYP} 2 \mathrm{C} 19^{\star} 1$. As a result of the greater incidence of PMs in Asian populations, a previous Japanese phase I study enrolled both EMs and PMs into separate cohorts based on the pre-treatment test for CYP2C19 polymorphism (ARQ 197-0701; Yamamoto et al, 2013). This study evaluated the safety of tivantinib as a single agent in solid tumours and found haematological toxicities to be the most common adverse events (AEs) related to tivantinib, regardless of CYP2C19 genotype. On the basis of that study, $360 \mathrm{mg}$ BID and $240 \mathrm{mg}$ BID were identified as recommended doses of tivantinib as a single agent for EMs and PMs, respectively, in the Asian population.

Here we report two open-label phase I studies that evaluated the safety and tolerability of tivantinib in combination with erlotinib among Japanese patients with NSCLC, and identified the recommended phase II doses (RP2Ds). Based on the pre-treatment test for CYP2C19 polymorphism, EMs and PMs were enrolled in ARQ 197-003 and ARQ 197-005 studies, respectively. Primary objectives were to evaluate the safety and tolerability of the combination with continuous daily dosing. Secondary objectives were to evaluate the preliminary antitumour activity and pharmacokinetics. PK evaluation of the dietary effects was needed to match the Western phase III protocol (MARQUEE study), and was conducted only in EMs, who are the majority of the Japanese population (Scagliotti et al, 2012). Potential predictive biomarkers were also investigated.

\section{PATIENTS AND METHODS}

Study design. ARQ 197-003 (NCT01069757) and ARQ 197-005 (NCT01251796) were multicentre (two and eight institutes, respectively), open-label, dose-escalating Japanese phase I studies. Based on the genetic test of CYP2C19, EMs and PMs were enrolled in ARQ 197-003 and ARQ 197-005, respectively. Patients received a single dose of tivantinib monotherapy for PK analysis, and after 2-6 days off-drug, the patients started consecutive tivantinib in combination with erlotinib (150 mg QD). Tivantinib was supplied by the sponsor as capsules, and was orally administrated twice a day at least $1 \mathrm{~h}$ before or $2 \mathrm{~h}$ after a meal (i.e., between meals) or just after meals. As shown in Table 1, the tested doses were escalated from 300 to $360 \mathrm{mg}$ BID of tivantinib in ARQ 197-003 (EM study) and from 120 to $240 \mathrm{mg}$ BID in ARQ 197-005 (PM study). The maximum doses of these studies were decided based on the RP2Ds for tivantinib monotherapy in a previous Japanese phase I study (ARQ 197-0701; Yamamoto et al, 2013). Cohort expansion took place only if dose-limiting toxicity (DLT) was

ARQ 197-003 (EM patients)

\begin{tabular}{|l|l|l|c|c|}
\hline Cohort & Tivantinib & Erlotinib & Planned number & Actual number \\
\hline 1 & $300 \mathrm{mg} \mathrm{BID}$ between meals & $150 \mathrm{mg}$ QD between meals & $3+3$ Rule & $4^{\text {a }}$ \\
\hline 2 & $360 \mathrm{mg}$ BID between meals & $150 \mathrm{mg}$ QD between meals & 6 & 6 \\
\hline 3 & $360 \mathrm{mg}$ BID just after meals & $150 \mathrm{mg}$ QD between meals & 6 & 6 \\
\hline
\end{tabular}

ARQ 197-005 (PM patients)

\begin{tabular}{|l|l|l|c|c|}
\hline Cohort & Tivantinib & Erlotinib & Planned number & $3+3$ Rule \\
\hline 1 & $120 \mathrm{mg}$ BID just after meals & $150 \mathrm{mg}$ QD between meals & 3 \\
\hline 2 & $240 \mathrm{mg}$ BID just after meals & $150 \mathrm{mg}$ QD between meals & 6 \\
\hline
\end{tabular}

Abbreviations: $\mathrm{EM}=$ extensive metaboliser; $\mathrm{PM}=$ poor metaboliser.

${ }^{a}$ One patient was replaced because of tivantinib-unrelated adverse event that led to an insufficient compliance to evaluate the safety of the dose level. 
reported in one patient for each cohort during the tolerability evaluation period (defined as the interval from the first dose of tivantinib to day 29 of the combination therapy). Dose escalation stopped if DLTs were observed in two or more patients during one cohort. A DLT was an AE related to either or both of the investigational drugs (i.e., tivantinib and/or erlotinib), and was defined as grade $\geqslant 3$ non-haematological toxicity except for controllable nausea, vomiting and diarrhoea, and/or grade $\geqslant 4$ haematological toxicity. Toxicities were graded according to the Common Terminology Criteria for Adverse Events (CTCAE) v3.0. Patients were allowed to continue tivantinib treatment with erlotinib as long as there was no evidence of progression disease (PD) or safety issues.

These studies were conducted in accordance with institutional guidelines, Good Clinical Practice guidelines and the Declaration of Helsinki. Documented approvals from the Institutional Review Boards were obtained. All patients gave written informed consent.

Eligibility criteria. Patients with cytologically or histologically confirmed advanced or recurrent NSCLC were candidates for these studies. The patients also met the inclusion criteria: one or more prior regimens of chemotherapy or EGFR-TKI therapy, $\geqslant 20$ years of age, an Eastern Cooperative Oncology Group performance status (ECOG PS; Oken et al, 1982) of $\leqslant 1$, a life expectancy of $\geqslant 3$ months, adequate organ functions and contraception for a designated period. Patients were excluded if they had prior anticancer therapies within 4 weeks, blood transfusion and/or colony-stimulating factor therapy within 2 weeks, previous tivantinib treatment, family history of QTc-prolongation syndrome, digestive organ dysfunction affecting tivantinib and/or erlotinib absorption, symptomatic CNS metastasis, and an uncontrollable concurrent illness. Pregnant or lactating women were also excluded.

Patient evaluation. Baseline evaluation included vital signs, blood counts, serum biochemistry and electrocardiograms, as well as genotyping of CYP2C19 and tumour evaluation. Vital signs, blood counts and serum biochemistry were measured every week for the first 4 weeks, and thereafter, every 2 weeks. In addition, electrocardiograms were taken every 2 weeks, and tumour response was evaluated at 4 weeks after the beginning of treatment, and thereafter, every 6 weeks, according to the Response Evaluation Criteria in Solid Tumours (RECIST) version 1.0. (Therasse et al, 2000). Tumour evaluation was conducted based on objective response rate (ORR), which consists of complete response (CR) and partial response (PR), and disease control rate (DCR), which consists of CR, PR and stable disease (SD). Adverse events were assessed continuously throughout the studies.

Pharmacokinetics analysis. PK blood samples were obtained at protocol-defined time points after the first dose of tivantinib (before dosing and 1, 2, 4, 6, 10, 12 and $24 \mathrm{~h}$ following tivantinib), and after the first dose of the combination (before dosing and 1, 2, $4,6,10$ and $12 \mathrm{~h}$ following tivantinib on day 1 , and before dosing on days 15 and 29). Plasma samples were analysed using liquid chromatography/tandem mass spectrometry. Noncompartmental PK parameters were calculated using Phoenix WinNonlin 6.1 (Pharsight, Mountain View, CA, USA). Dietary effect was also tested in EMs by comparing the PK parameters between cohorts 2 (between meals) and cohort 3 (just after meals), as shown in Table 1.

Predictive biomarkers. Tumour tissue samples were provided as a part of archived tissue or fresh biopsied samples before the first dose of tivantinib, and plasma samples were obtained on the day of the first dose of tivantinib before treatment. Phospho-c-Met (p-cMet) and c-Met were determined by immunohistochemistry (IHC), by using anti-p-c-Met rabbit monoclonal (clone $130 \mathrm{H} 2$, Cell Signaling Technology, Inc., Danvers, MA, USA) and anti-c-
Met rabbit polyclonal (Santa Cruz Biotechnology, Inc., Dallas, TX, USA), c-Met amplification by fluorescence in situ hybridisation, serum HGF and plasma VEGF by enzyme-linked immunosorbent assay, and EGFR and KRAS mutation status by direct sequencing. Those analyses were conducted in a commercial laboratory (SRL, Inc., Tokyo, Japan) except for EGFR mutation status in some patients, for whom EGFR mutation status had been already diagnosed before their informed consent.

\section{RESULTS}

Patient characteristics. A total of 25 patients with advanced or recurrent NSCLC (EMs: $n=16$, PMs: $n=9$ ) were enrolled into two studies (ARQ 197-003 for EMs and ARQ 197-005 for PMs) from March 2010 to March 2011. The data cutoff date was 28 October 2011 in both studies. Extensive metabolisers and PMs were assigned to each cohort as described in Table 1. There was no notable difference in patient characteristics between EMs and PMs (Table 2).

Safety and tolerability. One of 16 patients in ARQ 197-003 was excluded from DLT evaluation because of the study medication compliance of below $75 \%$ and no DLT during the tolerability evaluation period. Among the remaining 24 patients in both

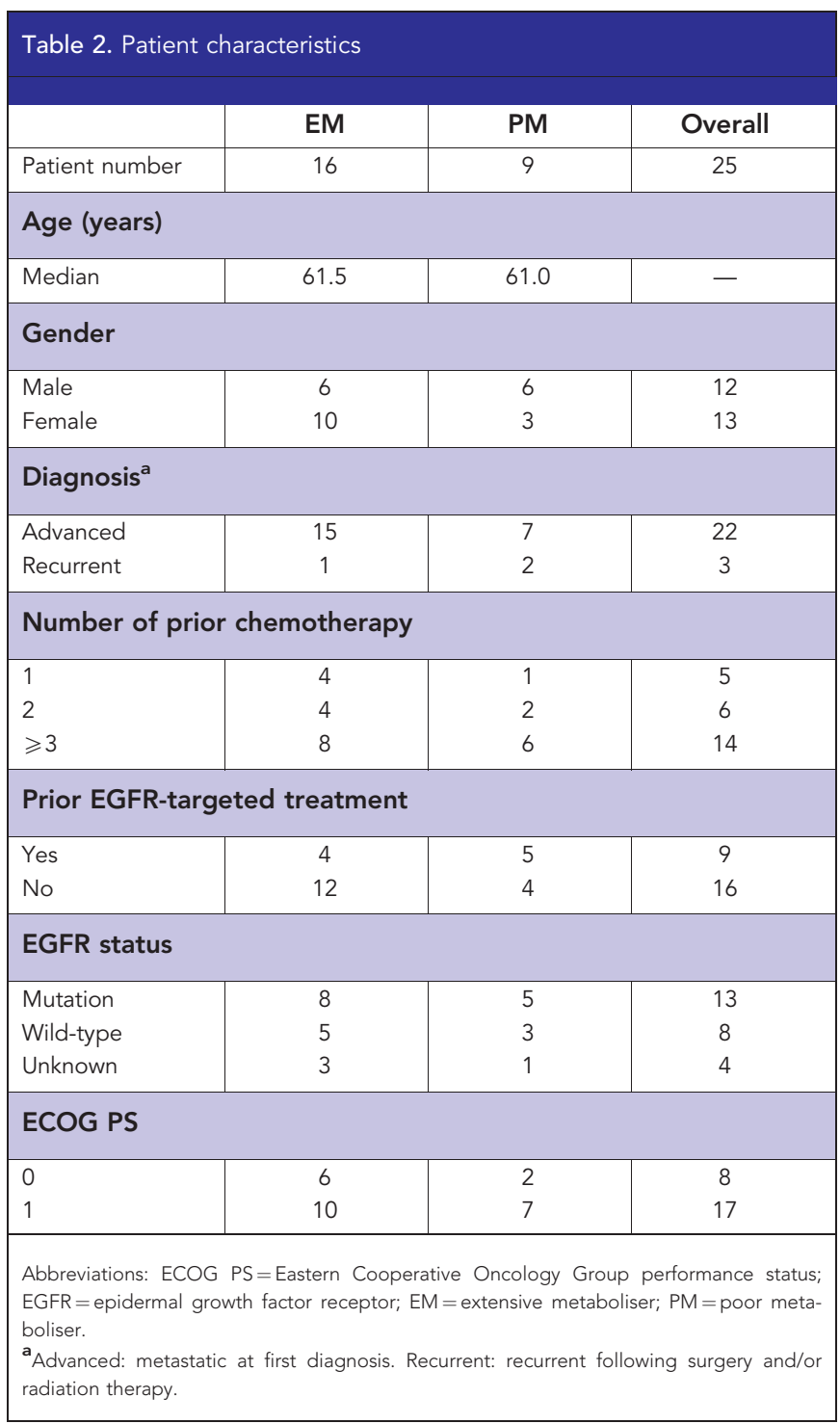


studies, no DLT was observed during the tolerability evaluation period. Tivantinib in combination with erlotinib was generally well tolerated. Grade 3 nausea and vomiting occurred in one EM patient during the tolerability evaluation period. This patient recovered from these events after antiemetic medications and 1 week of study drug interruption, and then was restarted on study drug at the initial doses with antiemetic prophylaxis.

At the time of the data cutoff, four patients (one in cohort 3 of EMs; one in cohort 1 and two in cohort 2 of PMs) have been ongoing while 21 patients had discontinued the treatment with the investigational drugs. Progression disease is the reason for the discontinuation in 20 of the 21 patients, except one neutropenia related to the investigational drugs, tivantinib and erlotinib. The neutropenia occurred on day 8 of the combination therapy, and the patient was withdrawn from this study according to a discontinuation criterion (i.e., interruption of investigational drugs lasting $>14$ days). The median duration from the first dose of tivantinib to the final dosing of tivantinib was 71.5 days (range, 1 to $258+$ ) for EMs and 134.0 days (range, 48 to $303+$ ) for PMs. One EM patient was discontinued because of PD before scheduled day 1 of the combination therapy.

Table 3 shows the common AEs related to the investigational drugs, and the events with a frequency of $>20 \%$ throughout the studies, in either or both EMs and PMs. Rash, diarrhoea, dry skin, nausea and stomatitis were commonly observed events in both EMs and PMs and were experienced in $>25 \%$ of patients. The grade $\geqslant 3$ drug-related AEs that were commonly observed throughout the studies were haematologic toxicities: leukopenia, anaemia and neutropenia. Those grade $\geqslant 3$ haematologic toxicities were prone to occur concurrently. A total of six grade $\geqslant 3$ haematologic toxicities occurred in three patients; one EM patient developed anaemia, one PM patient developed leukopenia, anaemia and neutropenia, and the remaining PM patient developed leukopenia and neutropenia. Almost all non-haematologic toxicities were grade $<2$, except controllable nausea, vomiting and rash. A suspicion of interstitial lung disease was reported in one patient three weeks after the last doses of investigational drugs.

One PM patient developed sepsis, which was recognised as a serious AE (SAE) related to the investigational drugs. The SAE required hospitalisation and treatment interruption of the investigational drugs. The sepsis occurred on day 53 of the combination therapy, with accompanying leukopenia and neutropenia, which had continued since day 30 . The patient recovered from the sepsis after 14 days by treatment with granulocyte colony-stimulating factor and antibiotics. However, during the recovering period, the patient developed a PD, which led to the discontinuation from this study.

Pharmacokinetics. Pharmacokinetic sampling was performed in all 25 patients. Figure 1 shows plasma concentration-time profiles of tivantinib after the first dose of tivantinib and on day 1 of the combination therapy. In EM cohort 3 (360 mg BID, just after meals), the plasma $\mathrm{AUC}_{0-12}$ of tivantinib was $18100 \pm 9400 \mathrm{ngh} \mathrm{ml}^{-1}$ for tivantinib monotherapy and $18800 \pm 7800 \mathrm{ng} \mathrm{h} \mathrm{ml}^{-1}$ for the combination. In the PM cohort 2 (240 mg BID, just after meals), the plasma $\mathrm{AUC}_{0-12}$ of tivantinib was $27200 \pm 5300 \mathrm{ngh} \mathrm{ml}^{-1}$ for tivantinib monotherapy and $27400 \pm 5800 \mathrm{ng} \mathrm{h} \mathrm{m}^{-1}$ for the combination. Poor metabolisers treated with $240 \mathrm{mg}$ BID of tivantinib showed moderately higher exposure of tivantinib than EMs treated with $360 \mathrm{mg} \mathrm{BID}$. On the other hand, the $\mathrm{AUC}_{0-12}$ was not obviously different in both EMs and PMs when tivantinib was administered alone or in combination with erlotinib. Dietary effects were also tested in EMs by comparing the PK parameters between cohorts 2 and 3, as shown in Table 1 . The $\mathrm{AUC}_{0-12}$ for the tivantinib monotherapy was similar between 'between meals' and 'just after meals', that is, $14800 \pm 7700$ and $18100 \pm 9400 \mathrm{ng} \mathrm{h} \mathrm{m}^{-1}$, respectively. Similarly, the $\mathrm{AUC}_{0-12}$ for the combination was similar between cohorts 2 and 3, that is, $20000 \pm 6100$ and $18800 \pm 7800 \mathrm{ng} \mathrm{hl}^{-1}$, respectively.

Table 3. Drug-related adverse events occurring $>20 \%$ of either or both of EMs and PMs, throughout the studies

\begin{tabular}{|c|c|c|c|c|c|c|}
\hline & \multicolumn{2}{|c|}{$\operatorname{EM}(n=16)$} & \multicolumn{2}{|c|}{$\mathrm{PM}(n=9)$} & \multicolumn{2}{|c|}{ Overall $(n=25)$} \\
\hline & All grades & $\geqslant \mathrm{Gr} .3$ & All grades & $\geqslant$ Gr.3 & All grades & $\geqslant \mathrm{Gr} .3$ \\
\hline & $n(\%)$ & n (\%) & $n(\%)$ & $n(\%)$ & $n(\%)$ & n (\%) \\
\hline \multicolumn{7}{|l|}{ Haematological } \\
\hline $\begin{array}{l}\text { Leukopenia } \\
\text { Anaemia } \\
\text { Neutropenia } \\
\text { Lymphopenia }\end{array}$ & $\begin{array}{l}3(19) \\
4(25) \\
1(6) \\
1(6)\end{array}$ & $\begin{array}{l}0(0) \\
1(6) \\
0(0) \\
0(0)\end{array}$ & $\begin{array}{l}3(33) \\
1(11) \\
2(22) \\
2(22)\end{array}$ & $\begin{array}{l}2(22) \\
1(11) \\
2(22) \\
0(0)\end{array}$ & $\begin{array}{l}6(24) \\
5(20) \\
3(12) \\
3(12)\end{array}$ & $\begin{array}{l}2(8) \\
2(8) \\
2(8) \\
0(0)\end{array}$ \\
\hline \multicolumn{7}{|l|}{ Non-haematological } \\
\hline $\begin{array}{l}\text { Rash } \\
\text { Diarrhoea } \\
\text { Dry skin } \\
\text { Nausea } \\
\text { Stomatitis } \\
\text { Dysgeusia } \\
\text { Anorexia } \\
\text { Other skin disorder } \\
\text { Fatigue } \\
\text { Nail disorder } \\
\text { Vomiting } \\
\text { Sinus bradycardia }\end{array}$ & $\begin{array}{l}13(81) \\
9(56) \\
8(50) \\
5(31) \\
5(31) \\
5(31) \\
4(25) \\
4(25) \\
3(19) \\
3(19) \\
4(25) \\
0(0)\end{array}$ & $\begin{array}{l}1(6) \\
0(0) \\
0(0) \\
1(6) \\
0(0) \\
0(0) \\
0(0) \\
0(0) \\
0(0) \\
0(0) \\
1(6) \\
0(0)\end{array}$ & $\begin{array}{l}9(100) \\
2(22) \\
3(33) \\
2(22) \\
2(22) \\
1(11) \\
2(22) \\
2(22) \\
3(33) \\
2(22) \\
0(0) \\
2(22)\end{array}$ & $\begin{array}{l}0(0) \\
0(0) \\
0(0) \\
0(0) \\
0(0) \\
0(0) \\
0(0) \\
0(0) \\
0(0) \\
0(0) \\
0(0) \\
0(0)\end{array}$ & $\begin{array}{l}22(88) \\
11(44) \\
11(44) \\
7(28) \\
7(28) \\
6(24) \\
6(24) \\
6(24) \\
6(24) \\
5(20) \\
4(16) \\
2(8)\end{array}$ & $\begin{array}{l}1(4) \\
0(0) \\
0(0) \\
1(4) \\
0(0) \\
0(0) \\
0(0) \\
0(0) \\
0(0) \\
0(0) \\
1(4) \\
0(0)\end{array}$ \\
\hline
\end{tabular}




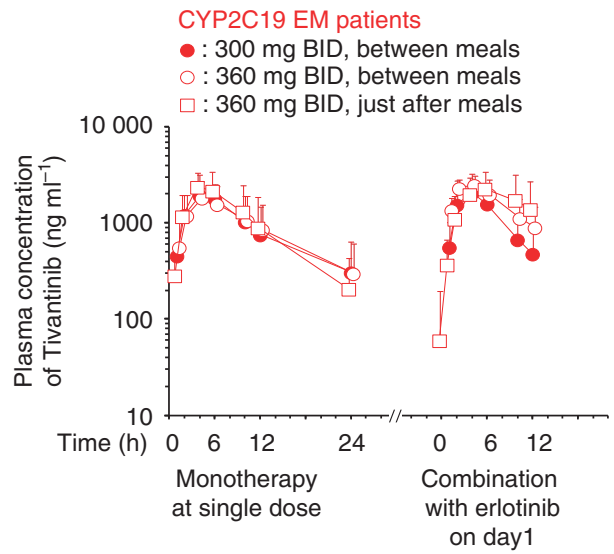

CYP2C19 PM patients

: $120 \mathrm{mg}$ BID, just after meals

$0: 240 \mathrm{mg} B I D$, just after meals

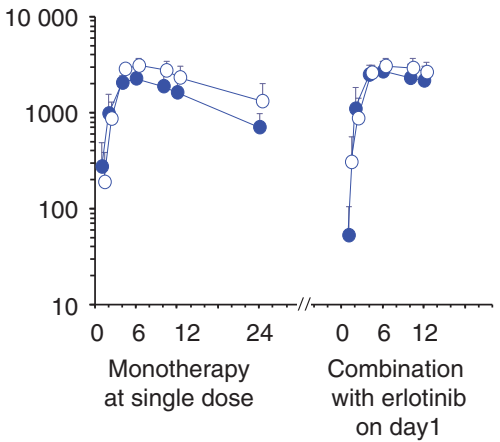

Figure 1. Pharmacokinetics profiles of tivantinib. Plasma concentration-time profiles of tivantinib after tivantinib monotherapy and the first dose of tivantinib in combination with erlotinib on day 1 are shown. Each point represents the mean \pm s.d. for EMs (left panel) and PMs (right panel), respectively.

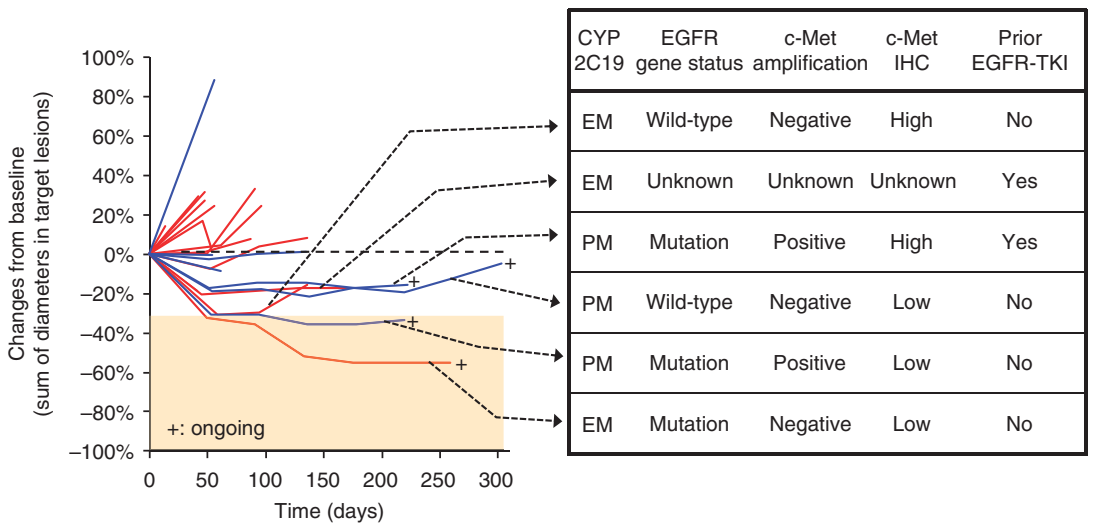

Figure 2. Spider plot and molecular properties of the six patients with a clinically meaningful efficacy. Changes of tumour sizes are shown for patients who had measurable lesions (22 of 25 patients). Sums of the diameters of the target lesions are demonstrated as changes from baseline. The red and blue lines indicate individual EM and PM, respectively. Molecular properties of tumours are shown for particular individual patients. Among the molecular properties, positive c-Met amplification was defined as $\geqslant 4$ copy numbers of c-Met gene (fluorescence in situ hybridisation). High c-Met IHC was defined as a higher IHC score than the median; all others were considered low (Supplement 1).

Efficacy and predictive biomarkers. All 25 patients in these studies were evaluable for tumour response, and the best overall response observed was: $3 \mathrm{PR}, 10 \mathrm{SD}, 9 \mathrm{PD}$ and 3 non-CR/PD. The ORR was $12.0 \%$ and the DCR was $52.0 \%$. Clinically meaningful efficacy was reported in 6 of 25 patients, including 3 PRs and 3 long-term SD of $>24$ weeks; 2 of $3 \mathrm{PR}$ patients experienced longterm disease control continuing $>24$ weeks on the combination therapy. Molecular properties of these six patients were shown in Figure 2 and those of all patients in Supplement 1. Of the three PR patients, one patient possessed wild-type EGFR with high expression of c-Met (IHC), whereas the other two patients possessed mutated EGFR with various c-Met expressions.

\section{DISCUSSION}

The dose-escalating phase I studies herein aimed to assess the safety, tolerability and RP2D of tivantinib in combination with the clinical dose of erlotinib (150 mg QD) in Japanese patients with NSCLC. The patients were separately enrolled in two studies (ARQ 197-003 and ARQ 197-005), which consisted of CYP2C19 EMs and PMs, respectively. The tested dose of tivantinib was up to $360 \mathrm{mg}$ BID for EMs and $240 \mathrm{mg}$ BID for PMs, which were RP2Ds for tivantinib monotherapy determined by a previous Japanese phase I study (ARQ 197-0701).
In the ARQ 197-003 that included only EMs, no DLT was observed in any cohort during the tolerability evaluation period. Throughout this study, anaemia, rash, nausea and vomiting comprised the grade $\geqslant 3$ AEs related to the investigational drugs. Each of the AEs occurred once in each of two patients, and resolved by adequate concomitant therapies or the study drug interruption. All these AEs are well known in either tivantinib or erlotinib monotherapies (Lynch et al, 2004; Mok et al, 2009; Yamamoto et al, 2013). Taken together, tivantinib treatment at the dose of up to $360 \mathrm{mg}$ BID (with or just after meals) in combination with erlotinib was tolerable and manageable in Japanese EMs with NSCLC. In addition, the AUC (geometric mean) of tivantinib in Japanese NSCLC patients (EM) at $360 \mathrm{mg}$ BID (just after meals) in combination with erlotinib was approximately two-fold higher than that of Caucasians under the same conditions (Goldman et al, 2012). Furthermore, the DCR in EMs in this study (50.0\%) was not remarkably different from that observed in the phase II Western clinical trial (ARQ 197-209, 64.4\%; Sequist et al, 2011). Therefore, we determined the RP2D in Japanese EMs to be $360 \mathrm{mg}$ BID just after meals, although no DLT was observed in EMs during the tolerability evaluation period in any cohort. This dose and usage are the same as those in phase III studies in Western countries, where EMs comprise the majority of patients.

Similarly, in the ARQ 197-005 trial, which included only PMs, no DLT was observed in any cohort during the tolerability evaluation period. Throughout this study, anaemia, leukopenia, 
neutropenia and sepsis comprised the grade $\geqslant 3$ AEs related to the investigational drugs. These AEs were observed in two of the six patients in cohort 2 ( $240 \mathrm{mg}$ BID) but were resolved by adequate concomitant therapy and/or drug interruption. All these AEs are well-known for either tivantinib or erlotinib as a single agent (Yamamoto et al, 2013). Hence, tivantinib treatment at a dose of up to $240 \mathrm{mg}$ BID (just after meals) in combination with erlotinib was well tolerated in Japanese PMs with NSCLC. PK analysis in this study demonstrated that plasma exposure of tivantinib in PMs at $240 \mathrm{mg}$ BID (just after meals) was higher than that observed for EMs at $360 \mathrm{mg}$ BID (just after meals). Thus, dose escalation was suspended in PMs at the $240 \mathrm{mg}$ BID dose, although no DLT was observed in PMs during the tolerability evaluation period in any cohort. Regarding efficacy, despite the fact that PMs received smaller doses of tivantinib than EMs, DCR in PMs in this study (55.5\%) was not remarkably different from both DCRs in EMs in this study $(50.0 \%)$ or in comparison with the phase II Western clinical trial (ARQ 197-209, 64.4\%; Sequist et al, 2011). Therefore, the RP2D in Japanese PMs was determined to be $240 \mathrm{mg}$ BID when administered just after meals.

In both the ARQ 197-003 and ARQ 197-005 studies, the common non-haematological toxicities related to the investigational drugs were rash, diarrhoea and dry skin, which were not common for tivantinib monotherapy in the previous study (Yamamoto et al, 2013). It is widely known that rash, diarrhoea and dry skin are among the most common AEs related to erlotinib as a single agent (Lynch et al, 2004; Mok et $a l, 2009)$. On the other hand, the common haematological toxicities related to the investigational drugs were neutropenia, leukopenia and anaemia. In contrast to non-haematological toxicities, these haematological toxicities have not been frequently observed in erlotinib monotherapy, but were very common in tivantinib monotherapy (Yamamoto et al, 2013). Therefore, tivantinib treatment in combination with erlotinib resulted in only known haematologic or non-haematologic toxicities observed in tivantinib or erlotinib alone. Furthermore, the combination did not increase the incidence of known toxicities in each monotherapy. Thus, tivantinib was compatible with erlotinib when it was administered up to the RP2Ds determined in these studies.

In these studies, the clinically meaningful activities, such as PR, long-term SD or disease control, were seen in six NSCLC patients with various molecular properties (i.e., EGFR mutation, c-Met amplification and c-Met high expression). In two of the six patients in whom the combination treatment of tivantinib and erlotinib resulted in clinically meaningful outcomes, our biomarker study implied c-Met contribution in their disease progression of NSCLC; one patient possessed wild-type EGFR with c-Met high expression, whereas the other patient possessed mutated EGFR with c-Met amplification. Owing to the small sample size of these studies, the specific biomarkers associated with the clinical benefits of combination therapy could not be identified. However, these studies might be encouraging for further trials to evaluate the efficacies of this combination in various molecularly diagnosed NSCLCs. Recently, the Western phase III MARQUEE study enrolled approximately 1000 NSCLC patients irrespective of EGFR mutation and c-Met expression status but was halted early because of futility in a planned interim analysis. Further exploratory analyses were performed, and the MET high tivantinib group showed a substantial improvement in OS relative to control (Scagliotti et al, 2013).

In conclusion, tivantinib, when combined with erlotinib, was well tolerated up to $360 \mathrm{mg}$ BID for EMs and $240 \mathrm{mg}$ BID for PMs, and therefore these doses were determined as RP2Ds. These results warrant further investigation of this combination in phase II NSCLC studies conducted in the Japanese/Asian population.

\section{ACKNOWLEDGEMENTS}

We thank the patients, their families, caregivers and all of the personnel who contributed to patient care and data collection for these studies of tivantinib. These studies were sponsored by Kyowa Hakko Kirin Co., Ltd.

\section{REFERENCES}

Beviglia L, Matsumoto K, Lin CS, Ziober BL, Kramer RH (1997) Expression of the c-Met/HGF receptor in human breast carcinoma: correlation with tumor progression. Int J Cancer 74: 301-309.

Comoglio PM, Giordano S, Trusolino L (2008) Drug development of MET inhibitors: targeting oncogene addiction and expedience. Nat Rev Drug Discov 7: 504-516.

Eathiraj S, Palma R, Volckova E, Hirschi M, France DS, Ashwell MA, Chan TC (2011) Discovery of a novel mode of protein kinase inhibition characterized by the mechanism of inhibition of human mesenchymalepithelial transition factor (c-Met) protein autophosphorylation by ARQ 197. J Biol Chem 286: 20666-20676.

Ferlay J, Shin HR, Bray F, Forman D, Mathers C, Parkin DM (2010) Estimates of worldwide burden of cancer in 2008: GLOBOCAN 2008. Int J Cancer 127: 2893-2917.

Goldman JW, Laux I, Chai F, Savage RE, Ferrari D, Garmey EG, Just RG, Rosen LS (2012) Phase 1 dose-escalation trial evaluating the combination of the selective MET (mesenchymal-epithelial transition factor) inhibitor tivantinib (ARQ 197) plus erlotinib. Cancer 118: 5903-5911.

Jemal A, Siegel R, Ward E, Hao Y, Xu J, Murray T, Thun MJ (2008) Cancer statistics, 2008. CA Cancer J Clin 58: 71-96.

Kubota T, Chiba K, Iga T (2001) Frequency distribution of CYP2C19, CYP2D6, and CYP2C9 mutant-alleles in several different populations. Xenobio Metab Dispos 16: 69-74.

Lynch TJ, Bell DW, Sordella R, Gurubhagavatula S, Okimoto RA, Brannigan BW, Harris PL, Haserlat SM, Supko JG, Haluska FG, Louis DN, Christiani DC, Settleman J, Haber DA (2004) Activating mutations in the epidermal growth factor receptor underlying responsiveness of non-small-cell lung cancer to gefitinib. N Engl J Med 350: 2129-2139.

Mitsudomi T, Yatabe Y (2007) Mutations of the epidermal growth factor receptor gene and related genes as determinants of epidermal growth factor receptor tyrosine kinase inhibitors sensitivity in lung cancer. Cancer Sci 98: 1817-1824.

Mok TS, Wu YL, Thongprasert S, Yang CH, Chu DT, Saijo N, Sunpaweravong P, Han B, Margono B, Ichinose Y, Nishiwaki Y, Ohe Y, Yang JJ, Chewaskulyong B, Jiang H, Duffield EL, Watkins CL, Armour AA, Fukuoka M (2009) Gefitinib or carboplatin-paclitaxel in pulmonary adenocarcinoma. $N$ Engl J Med 361: 947-957.

Oken MM, Creech RH, Tormey DC, Horton J, Davis TE, McFadden ET, Carbone PP (1982) Toxicity and response criteria of the Eastern Cooperative Oncology Group. Am J Clin Oncol 5: 649-655.

Qian CN, Guo X, Cao B, Kort EJ, Lee CC, Chen J, Wang LM, Mai WY, Min HQ, Hong MH, Vande Woude GF, Resau JH, Teh BT (2002) Met protein expression level correlates with survival in patients with late-stage nasopharyngeal carcinoma. Cancer Res 62: 589-596.

Qiao H, Hung W, Tremblay E, Wojcik J, Gui J, Ho J, Klassen J, Campling B, Elliott B (2002) Constitutive activation of Met kinase in non-small-cell lung carcinomas correlates with anchorage-independent cell survival. J Cell Biochem 86: 665-677.

Scagliotti G, Novello S, Ramlau R, Favaretto A, Barlesi F, Akerley W, Von Pawel J, Shuster D, Schwartz B, Sandler A (2013) MARQUEE: A randomized, double-blind, placebo-controlled, phase 3 trial of tivantinib (ARQ 197) plus erlotinib versus placebo plus erlotinib in previously treated patients with locally advanced or metastatic, non-squamous, non-small-cell lung cancer (NSCLC). ESMO congress: Abstract 3410.

Scagliotti GV, Novello S, Schiller JH, Hirsh V, Sequist LV, Soria JC, von Pawel J, Schwartz B, Von Roemeling R, Sandler AB (2012) Rationale and design of MARQUEE: a phase III, randomized, double-blind study of tivantinib plus erlotinib versus placebo plus erlotinib in previously treated patients with locally advanced or metastatic, nonsquamous, non-small-cell lung cancer. Clin Lung Cancer 13: 391-395. 
Scordo MG, Pengo V, Spina E, Dahl ML, Gusella M, Padrini R (2002) Influence of CYP2C9 and CYP2C19 genetic polymorphisms on warfarin maintenance dose and metabolic clearance. Pharmacol Ther 72: 702-710.

Sequist LV, von Pawel J, Garmey EG, Akerley WL, Brugger W, Ferrari D, Chen Y, Costa DB, Gerber DE, Orlov S, Ramlau R, Arthur S, Gorbachevsky I, Schwartz B, Schiller JH (2011) Randomized phase II study of erlotinib plus tivantinib versus erlotinib plus placebo in previously treated non-small-cell lung cancer. J Clin Oncol 29: 3307-3315.

Sharma SV, Bell DW, Settleman J, Haber DA (2007) Epidermal growth factor receptor mutations in lung cancer. Nat Rev Cancer 7: 169-181.

Sim SC, Risinger C, Dahl ML, Aklillu E, Christensen M, Bertilsson L, Ingelman-Sundberg M (2006) A common novel CYP2C19 gene variant causes ultrarapid drug metabolism relevant for the drug response to proton pump inhibitors and antidepressants. Clin Pharmacol Ther 79: $103-113$.

Suda K, Mizuuchi H, Maehara Y, Mitsudomi T (2012) Acquired resistance mechanisms to tyrosine kinase inhibitors in lung cancer with activating epidermal growth factor receptor mutation-diversity, ductility, and destiny. Cancer Metastasis Rev 31: 807-814.

Takeuchi H, Bilchik A, Saha S, Turner R, Wiese D, Tanaka M, Kuo C, Wang HJ, Hoon DS (2003) c-Met expression level in primary colon cancer: a predictor of tumor invasion and lymph node metastases. Clin Cancer Res 9: 1480-1488.

Tavian D, De Petro G, Benetti A, Portolani N, Giulini SM, Barlati S (2000) $\mathrm{u}-\mathrm{PA}$ and c-Met mRNA expression is co-ordinately enhanced while hepatocyte growth factor mRNA is down-regulated in human hepatocellular carcinoma. Int J Cancer 87: 644-649.

Therasse P, Arbuck SG, Eisenhauer EA, Wanders J, Kaplan RS, Rubinstein L, Verweij J, Van Glabbeke M, van Oosterom AT, Christian MC, Gwyther SG (2000) New guidelines to evaluate the response to treatment in solid tumors: European Organization for Research and Treatment of Cancer, National Cancer Institute of the United States, National Cancer Institute of Canada. J Natl Cancer Inst 92: 205-216.

Trusolino L, Bertotti A, Comoglio PM (2001) A signaling adapter function for a634 integrin in the control of HGF-dependent invasive growth. Cell 107: 643-654.

Yamamoto N, Murakami H, Nishina T, Hirashima T, Sugio K, Muro K, Takahashi T, Naito T, Yasui H, Akinaga S, Koh Y, Boku N (2013) The effect of CYP2C19 polymorphism on the safety, tolerability, and pharmacokinetics of tivantinib (ARQ 197): results from a phase I trial in advanced solid tumors. Ann Oncol 24(6): 1653-1659.

Yap TA, de Bono JS (2010) Targeting the HGF/c-Met axis: state of play. Mol Cancer Ther 9: 1077-1079.

This work is published under the standard license to publish agreement. After 12 months the work will become freely available and the license terms will switch to a Creative Commons AttributionNonCommercial-Share Alike 3.0 Unported License.

Supplementary Information accompanies this paper on British Journal of Cancer website (http://www.nature.com/bjc) 